\title{
Dispersal and molecular characterisation of the Echinococcus granulosus (Batsch, 1786) complex isolated from various intermediate hosts in the Calabria region, southern Italy
}

\author{
Grazia Pavia $^{1}$, Federica De Gori ${ }^{1}$, Lucia Ciambrone ${ }^{1}$, Natalino De Gori ${ }^{2}$, Rosanna Musarella ${ }^{1}$ and Francesco \\ Casalinuovo ${ }^{1}$
}

${ }^{1}$ Istituto Zooprofilattico Sperimentale del Mezzogiorno, Section of Catanzaro, Italy;

${ }^{2}$ Azienda Sanitaria Provinciale di Catanzaro, Catanzaro, Italy

\begin{abstract}
Cystic echinococcosis (CE) is a zoonotic disease caused by the tapeworms of the Echinococcus granulosus sensu lato complex, which have worldwide distribution. No data on the circulation of genotypes of the E. granulosus complex in intermediate hosts in endemic areas in Calabria are available. The aims of our study were to evaluate the dispersal of genotypes of the E. granulosus complex in Calabria and to characterise parasite isolates by Sanger sequencing and phylogenetic analysis. We collected 71 animal samples from pigs, wild boars, sheep, cattle and goats. The first PCR screening analysis targeted three partial genomic regions: the cytochrome c oxidase subunit 1 (cox 1 ), calreticulin protein ( $c a l)$ and NADH dehydrogenase subunit 1 (nad1); this identified 28 parasitic cysts. Bidirectional sequencing of cox 1 amplicons and phylogenetic analysis allowed us to characterise all isolates. Molecular analyses of 28 newly generated cox 1 sequences revealed that most wild boars $(\mathrm{n}=16)$ and three pigs were parasitised by the larval stage of Taenia hydatidena Pallas, 1766, called cysticercus tenuicollis. Two isolates from wild boars were identified as Echinococcus canadensis Webster and Cameron, 1961 (G7), while five sheep and two goats were infected with E. granulosus G1 (sheep strain) and G1 microvariant (previously reported as G2 genotype or Tasmanian sheep strain), respectively. These molecular findings should prompt further and more extensive studies, to elucidate regional transmission patterns and to guide control programs.
\end{abstract}

Keywords: Echinococcus canadensis G7, G1 microvariant of E. granulosus s.s., Cystic echinococcosis, wild boars, goats, zoonoses, sanger sequencing, molecular characterisation, genotyping

Cystic echinococcosis (CE) is a cosmopolitan zoonosis caused by the larval stage of tapeworms of the Echinococcus granulosus (Batsch, 1786) sensu lato complex, and constitutes a serious health problem in a "one-health" perspective. Despite the heavy economic impact on public health and the livestock trade (Seimenis 2003), the real burden of this parasitic infectious disease, which is classified as neglected in the WHO's European Region (Da Silva 2010, Deplazes et al. 2017), is poorly understood.

$\mathrm{CE}$ has a worldwide geographic distribution, being found in Europe, Africa, Australia and the Americas, and displays regional or local differences related to the spectrum of intermediate hosts and other factors (Eckert et al. 2001, Thompson and McMannus 2002, EFSA 2018). In Italy, retrospective studies have revealed an increased risk of human CE, particularly in the Islands and the southern regions, where sheep breeding is widely practised, and the prevalence of CE is highest in sheep (Garippa 2006, Brundu et al. 2014).
The E. granulosus s.l. complex is genetically highly heterogeneous. Traditionally, the identification and characterisation of species and subspecies (variants or genotypes) was based on a combination of biological, epidemiological and morphological criteria (Thompson and McManus 2002). In recent years, however, progress in mitochondrial phylogenetic analyses has allowed the different genotypes to be grouped into five species: E. granulosus sensu stricto (E. granulosus s.s.: G1-G3), Echinococcus equinus (Williams and Sweatman, 1963) (G4), Echinococcus ortleppi (Lopez-Neyra and Soler Planas, 1943) (G5), Echinococcus canadensis (G6/G7/G8/G10) and Echinococcus felidis (Ortlepp, 1937), all of which cause unilocular echinococcosis (Nakao et al. 2007; Saarma et al. 2009).

The species included in Echinococcus genus show clear differences in terms of their intermediate hosts, geographical distribution, genetic variability and ability to infect humans (McManus 2013). However, the role of different genotypes in this complex and their impact on human and animal health still need further investigation (Hosseini-Sa-

Address for correspondence: F. Casalinuovo, Istituto Zooprofilattico Sperimentale del Mezzogiorno, Section of Catanzaro, Italy, Viale Crotone snc, 88100 Catanzaro, Italy. Phone: +39 0961737763, Fax: +39 0961738088, E-mail: francesco.casalinuovo@cert.izsmportici.it 
Table 1. List of primer of three PCR protocols used to discriminate between the Echinococcus granulosus complex, E. granulosus sensu stricto (G1/G3) and Echinococcus canadensis (G6/G7).

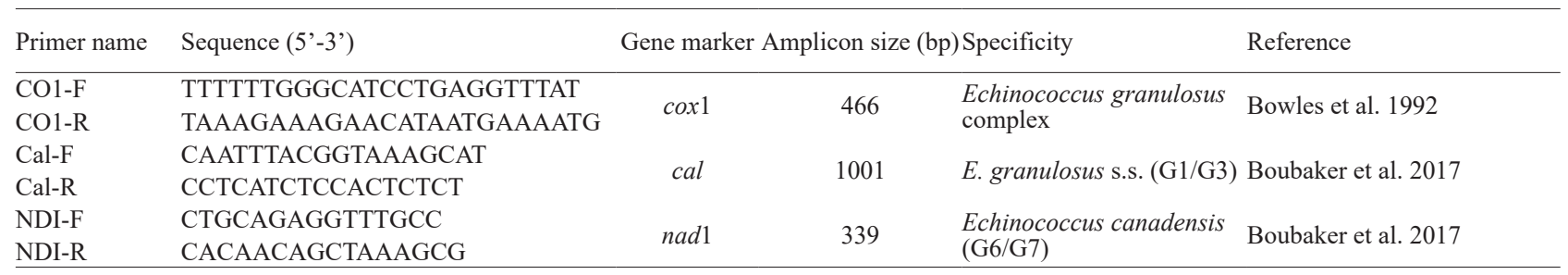

fa et al. 2016, Laurimäe et al. 2018a,b). Several studies have reported that E. granulosus s.s. and E. canadensis (G6/G7) are the most prevalent species that infect humans (Alvarez Rojas et al. 2014, Cucher et al. 2016).

Echinococcus granulosus s.s. has a cosmopolitan distribution and includes sheep (G1) and buffalo (G3) strains (Hosseini-Safa et al. 2016, Kinkar et al. 2017). It is responsible for the great majority of cases of human CE worldwide $(88 \%)$, and is often associated with transmission via sheep as the intermediate host. Recently, Kinkar et al. (2017) conducted a study on the mitogenome and nuclear DNA of this species complex. This study revealed that genotypes G1 and G3 could be treated as distinct genotypes only at the mitochondrial level.

Echinococcus canadensis (G6/G7) has been reported in $11 \%$ of cases worldwide, with the G6 genotype being responsible for $7 \%$ of infections, whereas G7 strain for $4 \%$ of human cases transmitted mainly by pigs (Alvarez Rojas et al. 2014). However, E. granulosus (G6/G7) has also been reported in various hosts: moose, deer and caribou (Schurer et al. 2013), goats (Soriano et al. 2010), camels (Namaware and Dahiya 2018), cattle (Zhang et al. 1998, Wachira et al. 1993) and wild boars (Kedra et al. 2000, Mwambete et al. 2004).

In many European regions, the number of wild boars has increased considerably in recent years, and these animals have been reported to play an important role as intermediate hosts in the epidemiology and transmission of several diseases to livestock and humans (Meng et al. 2009, Casalinuovo et al. 2017, Fredriksson-Ahomaa 2019, Sgroi et al. 2019). Indeed, various Italian studies have reported evidence of the E. granulosus genotype complex in this wild ungulate (Di Paolo et al. 2017, Paoletti et al. 2019, Sgroi et al. 2019).To date, however, few studies have reported the presence of genotypes of the E. granulosus complex in wild boar, and data on their molecular characterisation and dispersal in endemic areas in southern Italy are absent.

The aims of the present study were therefore to determine the dispersal of $\mathrm{CE}$ in various domestic and wild intermediate hosts, and to characterise, by means of molecular approaches, the genotypes of the E. granulosus complex circulating in endemic areas of the Calabria region, southern Italy.

\section{MATERIALS AND METHODS}

\section{Sample collection}

From November 2017 to September 2019, a total of 71 samples were collected from pigs, wild boars, cattle, sheep and goats with suspected hydatidosis during routine meat inspection in Calabria. In particular, we focused on the carcasses of home-slaughtered pigs and wild boars killed during the hunting season, which were examined by specialised veterinarians. Parasitised organs of intermediate hosts were transported within $24 \mathrm{~h}$ to the Istituto Zooprofilattico Sperimentale del Mezzogiorno, Section of Catanzaro, Italy (IZSM), Catanzaro and carefully examined for the presence of presumptive hydatid cysts by means of visual inspection, palpation and serial section of the organs. Each cyst was treated as an isolate, transferred to a Petri dish and dissected. The germinal layers were washed three times with phosphate-buffered saline (PBS) pH 7.0 and stored in ethanol 70\% until DNA extraction.

\section{DNA extraction and PCR amplification}

The DNA of each isolate was extracted from ethanol-preserved cysts by means of a Qiamp DNA Mini kit (Qiagen, Hilden, Germany) from approximately $25 \mathrm{mg}$ of germinal layer, according to the manufacturer's recommendations. DNA was eluted with $150 \mu \mathrm{l}$ of sterile water and stored at $-20^{\circ} \mathrm{C}$ until molecular analysis. The Echinococcus granulosus complex and its different genotypes were identified by means of polymerase chain reaction (PCR) and DNA sequencing of partial mitochondrial and nuclear genes. The isolates were initially screened by implementing three PCR protocols for the amplification of the cytochrome c oxidase subunit 1 (cox1) (Bowles et al. 1992), calreticulin protein ( $\mathrm{cal}$ ) and NADH dehydrogenase subunit 1 (nad1) (Boubaker et al. 2017) in order to distinguish the E. granulosus complex from the G1/G2/G3 and G6/7 genotypes (Table 1). The PCR products were purified by means of the PCR Illustra MicroSpin S-300 Column HR (Gelifesciences, Amersham, UK) in accordance with the manufacturer's instructions.

\section{DNA sequencing and phylogenetic analysis}

The purified PCR cox 1 amplicons were sequenced by means of the ABI PRISM 3500 genetic analyser sequencer (Applied Biosystems, Foster City, CA, USA). Sequencing was performed in both directions, using the same primers as in the three PCR protocols (see above), by means of the BigDye Terminator v1.1 cycle sequencing kit. Newly generated sequences were aligned by means of Clustal W (Thompson et al. 1994) and manually edited in Chromas v. 2.6.4. Blast software (http://www.ncbi.nlm. nih.gov) was used to compare the cox 1 sequences obtained with those deposited in GenBank, in order to preliminarily identify the genotype of the hydatid cyst isolates. A phylogenetic tree was generated by means of the MEGA v.7.0 program (Kumar et al. 2016). Taenia saginata (Goeze, 1782) was used as the out-group. The Neighbor-joining method (Saitou and Nei 1987) was used, together with the Tajima-Nei method (Tajima and Nei 1984), to compute evolutionary distances, which are presented in the units 
Table 2. Characteristics of animal samples collected.

\begin{tabular}{lcc}
\hline Animal host & Origin of parasite isolates & Numbers of samples \\
\hline Wild boar & liver & 20 \\
& spleen & 1 \\
& mesenterium & 1 \\
& diaphragm & 3 \\
Sheep & liver & 9 \\
& lungs & 5 \\
Pig & liver & 19 \\
Cattle & liver & 7 \\
& lungs & 4 \\
Goat & liver & 1 \\
& lungs & 1 \\
& Total samples & $\mathbf{7 1}$ \\
\hline
\end{tabular}

as the number of base substitutions per site. The reliability of phylogenetic clustering was evaluated by means of 1,000 bootstrap replicates. The cox 1 sequences were deposited in the GenBank database (Benson et al. 2014) under the accession numbers MN582430-MN582457.

\section{RESULTS}

\section{Hydatid cyst collection}

During routine meat inspection, 71 hydatid-like cysts were collected and their germinal layers fixed in $70 \%$ ethanol. The characteristics of the animal samples are summarised in Table 2. Parasite isolates were derived from several organs: liver, lung, spleen, mesenterium and diaphragm from pigs $(n=19)$, wild boars $(n=25)$, sheep $(n=14)$, cattle $(n=11)$ and goats $(n=2)$. Most of the wild boar samples that had proved positive on veterinary visual examination had hydatid-like cysts in the liver $(20 / 25,80 \%)$, diaphragm $(3 / 25,12 \%)$, mesenterium $(1 / 25,4 \%)$ and spleen $(1 / 25,4 \%)$; these organs often showed massive infection, with several "daughter" cysts. The examined organs are described in Table 2.

\section{Amplification of cox 1, cal and nad1 partial genes}

On initial molecular investigation, 28 cysts showed amplification on at least one of the PCR protocols (Table 3). All isolates were positive for cox 1 partial region, which identified all genotypes included in the Echinococcus granulosus complex. Of these, isolates from five sheep and two goats proved to be infected with $E$. granulosus s.s. (G1/G2/ G3); two samples from wild boars, which were positive on the nad 1 PCR protocol, were identified as Echinococcus canadensis (G6/G7) isolates (Table 3). This first molecular approach did not allow us to distinguish between G1 and G3 or between G6 and G7 genotypes.

\section{Molecular analyses}

The initial molecular screening was carried out by means of PCR testing of three partial genomic regions ( $\operatorname{cox} 1$, nad 1 and $c a l)$, followed by DNA Sanger sequencing and phylogenetic analysis. This allowed us to character- ise and genotype all isolates. The 28 newly generated cox 1 sequences were analysed by means of BLAST similarity matches and multiple sequence alignment with reference sequences of genotypes of E. granulosus (downloaded from the GenBank database). Fig. 1 shows the phylogenetic tree of our isolates and the reference sequences. Molecular analyses revealed that most wild boar isolates and three pig isolates, which proved positive for the $E$. granulosus complex on PCR, were parasitised by another cestode; this larval stages of Taenia hydatigena, called cysticercus tenuicollis (Table 3 ). Out of a total of 18 wild boar sequences analysed, two isolates (ECHI 2 and ECHI 10) were E. granulosus (G7); five sheep (ECHI 32, ECHI 35, ECHI 36, ECHI 37, ECHI 54) and two goat samples (ECHI 72 and ECHI 73) were infected with E. granulosus G1 (sheep strain) and microvariant G1, respectively (Table $3)$. Overall, the phylogenetic analysis grouped seven of the 28 isolates (five sheep and two goats) in the clade with G1G3 reference sequences, with bootstrap support of $95 \%$. The two E. granulosus (G7) wild boar isolates, ECHI 2 and ECHI 10, formed a cluster, with bootstrap support of $69 \%$ (Fig. 1).

\section{DISCUSSION}

In agreement with previously reported European data (Loi et al. 2019), the findings of this study showed the prevalent occurrence of Echinococcus granulosus s.s. G1 in sheep. Our results also shed light on the epidemiology of $\mathrm{CE}$, in that they revealed the presence of the E. granulosus s.s. G1 microvariant (previously reported as G2 genotype or Tasmanian sheep strain) in goats, and of Echinococcus canadensis (G7) in wild boar in southern Italy.

The accurate diagnosis of infections due to the E. granulosus complex in domestic and wild intermediate hosts is central to investigating the real burden of $\mathrm{CE}$ and underpins appropriate control programs. In Italy, CE is endemic or hyperendemic in several regions, and is responsible for significant economic losses in the public health and livestock sectors (Veneziano et al. 2004, Capuano et al. 2006, Scala et al. 2006, Cringoli et al. 2007, Rinaldi et al. 2008).

Recently, Piseddu et al. (2017) reported 12,619 cases of $\mathrm{CE}$ in hospitalised patients, emphasising the need for further national studies to improve ad hoc information on this under diagnosed and "neglected" disease. Indeed, reports from the EFSA and the ECDC highlight the fact that there is no system of surveillance of human CE in Italy. As a result, no official data are transmitted to European authorities (EFSA 2018).

It is noteworthy that the few official data available on wild intermediate hosts, particularly wild boar, substantially under-represent the dispersal of the different genotypes of the E. granulosus complex in this important reservoir. Several studies have reported the circulation of E. granulosus $\mathrm{G} 1$ and G3 in wild boars in various Italian regions (Varcasia et al. 2008, Di Nicola et al. 2015, Di Paolo et al. 2017). Moreover, concurrently with our sampling, Sgroi et al. (2019) isolated the E. canadensis (G7) strain in a wild boar population in the Campania region. 


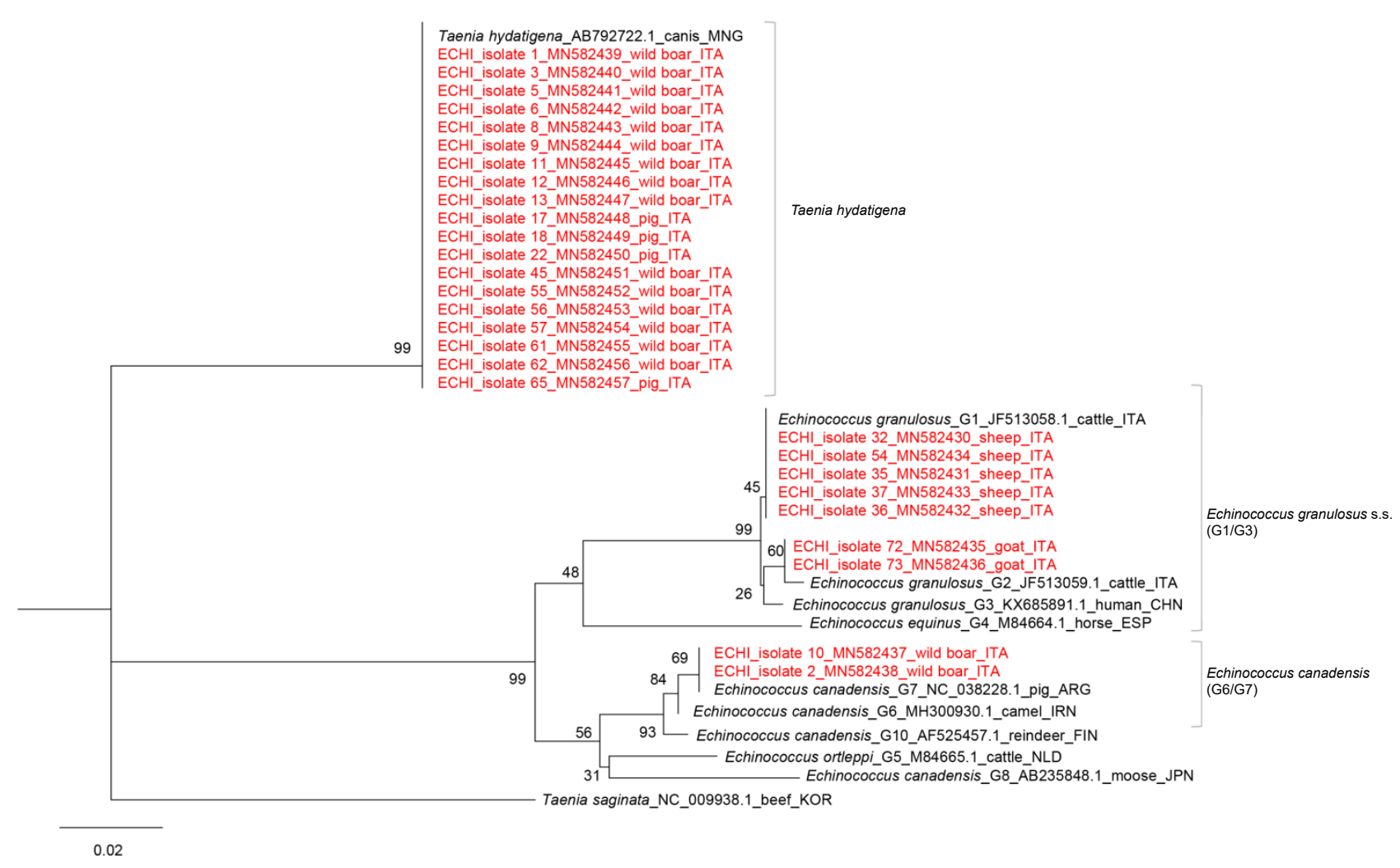

Fig. 1. The phylogenetic tree was estimated using reference sequences of the Echinococcus granulosus complex and Taenia hydatigena (black) downloaded from GenBank database and 28 parasite sequences isolated in this study (red). The tree was generated using Neighbor joining (NJ) method (Saitou and Nei 1984) based on an multi-alignment of partial sequences (466 bp) from cytochrome c oxidase I gene (cox 1$)$. The percentage of replicate trees in which the associated taxa clustered together in the bootstrap test (1,000 replicates) are shown next to the branches. The evolutionary distances were computed using the Tajima-Nei method (Tajima and Nei 1984) and are in the units of the number of base substitutions per site. All positions containing gaps and missing data were eliminated. Taenia saginata (NC_009938.1) was used as an outgroup. Phylogenetic analyses were conducted in MEGA7 (Kumar et al. 2013). The nucleotide sequences are shown with: isolate name, Accession No., host and country code (ARG - Argentina, CHN - China, ESP - Spain, FIN - Finland, IRN - Iran, ITA - Italy, JPN - Japan, MNG - Mongolia, NLD - Netherlands, KOR - South Korea).

In our study, we characterised 28 isolates from parasitic cysts by means of molecular analyses; of these, two wild boar isolates were E. canadensis (G7). Of the total number of parasitised organs examined, hydatid-like cysts in wild boars were found in $80 \%$ of liver samples $(20 / 25)$, $12 \%$ of diaphragm samples $(3 / 25)$, and $4 \%$ of both mesenterium and spleen samples (1/25); these organs frequently presented massive infection, with several 'daughter' cysts being observed. Massive infection have also been reported in other studies, and seem to be associated with age and recurrent infections (Scala et al. 2006, Otero-Abad and Torgerson 2013).

In the last few years, several European countries, including Italy, have seen a 'wild boar emergency'. Indeed, the overcrowding of these animals has led to a serious public health problem, as they are a crucial reservoir of various zoonoses (Casalinuovo et al. 2017). Moreover, it is important to point out that wild animals are possible indicators of the environmental spread of CE. The dispersion of infected animal carcasses (with parasitic cysts, tubercular lesions, etc.) during the hunting season could increase the load of infectious parasites in the environment and promote a spill-over from wild to domestic animals (Otero-Abad and Torgerson 2013).

In this scenario, the E. granulosus complex may have adapted to wildlife, circulating in the environment and exposing to $\mathrm{CE}$ infection other wild or domestic animals that have so far not been considered susceptible. The surveillance of $\mathrm{CE}$ is more difficult in wild animals than in domestic one. Therefore, the presence of E. canadensis (G7) in wild boar could play a crucial role in spreading $\mathrm{CE}$ to intermediate hosts, including humans.

Our study also identified the presence of the E. granulosus s.s. G1 microvariant (previously reported as G2 genotype or Tasmanian sheep strain) in goats. In Italy, the G1 microvariant has frequently been isolated from humans, sheep, cattle and also goats, which testifies to the fact that the "sheep strain" can adapt well to other reservoirs over time. The presence of mixed sheep and goat farms in Calabria has allowed E. granulosus s.s. to spread to goats.

Overall, our results confirmed the role of sheep as intermediate hosts of E. granulosus s.s. G1 in CE epidemiology. 
Table 3. Molecular characterisation of parasites isolated from different animal species using PCR method and Sanger DNA sequencing.

\begin{tabular}{|c|c|c|c|c|c|}
\hline \multirow{2}{*}{ Isolates_ID } & \multirow{2}{*}{ Animal species } & \multicolumn{3}{|c|}{ PCR Amplicon (+/-) } & \multirow{2}{*}{ Sequence-based genotyping } \\
\hline & & $\operatorname{cox} 1$ & cal & nad 1 & \\
\hline ECHI_isolate 1 & wild boar & + & - & - & Taenia hydatigena \\
\hline ECHI_isolate 2 & wild boar & + & - & + & Echinoccocus canadensis (G7) \\
\hline ECHI_isolate 3 & wild boar & + & - & - & Taenia hydatigena \\
\hline ECHI_isolate 5 & wild boar & + & - & - & Taenia hydatigena \\
\hline ECHI_isolate 6 & wild boar & + & - & - & Taenia hydatigena \\
\hline ECHI_isolate 8 & wild boar & + & - & - & Taenia hydatigena \\
\hline ECHI_isolate 9 & wild boar & + & - & - & Taenia hydatigena \\
\hline ECHI_isolate 10 & wild boar & + & - & + & E. canadensis $(\mathrm{G} 7)$ \\
\hline ECHI_isolate 11 & wild boar & + & - & - & Taenia hydatigena \\
\hline ECHI_isolate 12 & wild boar & + & - & - & Taenia hydatigena \\
\hline ECHI_isolate 13 & wild boar & + & - & - & Taenia hydatigena \\
\hline ECHI_isolate 17 & pig & + & - & - & Taenia hydatigena \\
\hline ECHI_isolate 18 & pig & + & - & - & Taenia hydatigena \\
\hline ECHI_isolate 22 & pig & + & - & - & Taenia hydatigena \\
\hline ECHI_isolate 32 & sheep & + & + & - & Echinococcus granulosus sensu stricto $(\mathrm{G} 1 / \mathrm{G} 3)$ \\
\hline ECHI_isolate 35 & sheep & + & + & - & Echinoccocus granulosus sensu stricto $(\mathrm{G} 1 / \mathrm{G} 3)$ \\
\hline ECHI_isolate 36 & sheep & + & + & - & Echinoccocus granulosus sensu stricto $(\mathrm{G} 1 / \mathrm{G} 3)$ \\
\hline ECHI_isolate 37 & sheep & + & + & - & Echinoccocus granulosus sensu stricto $(\mathrm{G} 1 / \mathrm{G} 3)$ \\
\hline ECHI_isolate 45 & wild boar & + & - & - & Taenia hydatigena \\
\hline ECHI_isolate 54 & sheep & + & + & - & Echinoccocus granulosus sensu stricto $(\mathrm{G} 1 / \mathrm{G} 3)$ \\
\hline ECHI_isolate 55 & wild boar & + & - & - & Taenia hydatigena \\
\hline ECHI_isolate 56 & wild boar & + & - & - & Taenia hydatigena \\
\hline ECHI_isolate 57 & wild boar & + & - & - & Taenia hydatigena \\
\hline ECHI_isolate 61 & wild boar & + & - & - & Taenia hydatigena \\
\hline ECHI_isolate 62 & wild boar & + & - & - & Taenia hydatigena \\
\hline ECHI_isolate 65 & pig & + & - & - & Taenia hydatigena \\
\hline ECHI_isolate 72 & goat & + & + & - & Echinoccocus granulosus sensu stricto $(\mathrm{G} 1 / \mathrm{G} 3)$ \\
\hline ECHI_isolate 73 & goat & + & + & - & Echinoccocus granulosus sensu stricto $(\mathrm{G} 1 / \mathrm{G} 3)$ \\
\hline
\end{tabular}

Moreover, our isolation of Echinococcus canadensis (G7) from hydatid cysts in wild boars, and our characterisation of E. granulosus s.s. G1 microvariant in goats helps to better understand of the dispersal of various genotypes of the E. granulosus complex in southern Italy. These findings should prompt further and more comprehensive molecular and epidemiological studies, in order to investigate regional transmission patterns and to guide control programs.

Acknowledgements. The authors thank the OIE Reference Laboratory for Echinococcosis, National Reference Laboratory for Cystic Echinococcosis (CeNRE), Istituto Zooprofilattico Sperimentale (IZS) of Sardinia for providing PCR E. granulosus positive control.

\section{REFERENCES}

Alvarez Rojas C.A., Romig T., Lightowlers M.W. 2014: Echinococcus granulosus sensu lato genotypes infecting humans review of current knowledge. Int. J. Parasitol. 44: 9-18.

Benson D.A., Clark K., Karsch-Mizrachi I., Lipman D.J., Ostell J., SAyers E.W. 2014: GenBank. Nucleic Acids Res. 42: 32-37.

Boubaker G., Macchiaroli N., Prada L., Cucher M.A., Rosenzit M.C., Ziadinov I., Deplazes P., Saarma U., Babba H., Gottstein B., Spiliotis M. 2017: A multiplex PCR for the simultaneous detection and genotyping of the Echinococcus granulosus complex. PLoS Negl. Trop. Dis. 7: e2017.

Bowles J., Blair D., McManus D.P. 1992: Genetic variants within the genus Echinococcus identified by mitochondrial DNA sequencing. Mol. Biochem. Parasitol. 54: 165-173.

Brundu D., Piseddu T., Stegel G., Masu G., Ledda S., MasaLA G. 2014: Retrospective study of human cystic echinococcosis in Italy based on the analysis of hospital discharge records between 2001 and 2012. Acta Trop. 140: 91-96.

Capuano F., Rinaldi L., Maurelli M.P., Perugini A.G., Veneziano V., Garippa G., Genchi C., Musella V., Cringoli G. 2006: Cystic echinococcosis in water buffaloes: epidemiological survey and molecular evidence of ovine (G1) and buffalo (G3) strains. Vet. Parasitol. 137: 262-268.
Casalinuovo F., Ciambrone L., Grillone R., De Gori N. 2017: Tuberculosis in wild boar and the risk of human infection by Mycobacterium bovis results of a study conducted in Southern Italy. J. Food Microbiol. 1: 22-26.

Cringoli G., Rinaldi L., Musella V., Veneziano V., Maurelli M.P., Di Pietro F., Frisiello M., Di Pietro S. 2007: Geo-referencing livestock farms as tool for studying cystic echinococcosis epidemiology in cattle and water buffaloes from southern Italy. Geospat. Hlth. 2: 105-111.

Cucher M.A., Macchiaroli N., Baldi G., Camicia F., Prada L., Maldonado L., Avila H.G., Fox A., Gutiérrez A., Negro P., López R., Jensen O., Rosenzvit M., Kamenetzky L. 2016: Cystic echinococcosis in South America: systematic review of species and genotypes of Echinococcus granulosus sensu lato in humans and natural domestic hosts. Trop. Med. Int. Health. 21: 166-175.

Da Silva A.M. 2010: Human echinococcosis: a neglected disease. Gastroenterol. Res. Pract. 2010: 583297.

Deplazes P., Rinaldi L., Alvarez Rojas C.A., Torgerson P.R., Harandi M.F., Romig T., Antolova D., Schurer J.M., Lahmar S., Cringoli G., Magambo J., Thompson R.C., JENKInS E.J. 2017: Global distribution of alveolar and cystic echinococcosis. Adv. Parasitol. 95: 315-493. 
Di Nicola U., Scacchia M., Marruchella G. 2015: Pathological and serological findings in wild boars (Sus scrofa) from gran Sasso and Monti della Laga National Park (Central Italy). Large Anim. Rev. 21: 167-171.

Di Paolo A., Piseddu T., Sebastianelli M., Manuali E., CorNeli S., Paniccià M., Papa P., Viali S., Mazzone P. 2017: Detection of Echinococcus granulosus G3 in a wild boar (Sus scrofa) in Central Italy using PCR and sequencing. J. Wildl. Dis. 53: 399-401.

Eckert J., Gemmell M.A., Meslin, F.-X., Pawowski Z.S. And World Health Organization. 2001: WHO/OIE Manual on Echinococcosis in Humans and Animals: a Public Health Problem of Global Concern. World Organisation for Animal Health, Paris, $107 \mathrm{pp}$.

EFSA and ECDC (European Food Safety Authority and European Centre for Disease Prevention and ConTROL). 2018: The European Union summary report on trends and sources of zoonoses, zoonotic agents and food-borne outbreaks in 2017. EFSA J. 16: 5500.

FREDRIKSSON-AHOMAA M. 2019: Wild boar: a reservoir of foodborne zoonoses. Foodborne Pathog. Dis. 16: 153-165.

GARIPPA G. 2006: Updates on cystic echinococcosis (CE) in Italy. Parassitologia 48: 57-59.

Hosseini-Safa A., Mohag Hegh M.A., Pestechian N., Ganji M., Mohammadi R., Mahmoudi Lamouki R., Rostami-NeJAD M. 2016: First report of Tasmanian sheep strain (G2) genotype isolated from Iranian goat using the high resolution melting (HRM) analysis. Gastroenterol. Hepatol. Bed. Bench. 9 (Suppl.1): S70-S74.

Kedra A.H., Tкасh V.V., Swiderski Z.P., Pawlowski Z., Emets A., Pawlowski J. 2000: Molecular characterisation of Echinococcus granulosus from a wild boar. Acta Parasitol. 45: 121-122.

Kinkar L., Laurimäe T., Sharbatkhori M., Mirhendi H., Kia E.B., Ponce-Gordo F., Andresiuk V., Simsek S., Lavikainen A., Irshadullah M., Umhang G., OudNi-M'rad M., Acosta-Jamett G., Rehbein S., Saarma U. 2017: New mitogenome and nuclear evidence on the phylogeny and taxonomy of the highly zoonotic tapeworm Echinococcus granulosus sensu stricto. Infect. Genet. Evol. 52: 52-58.

Kumar S., Stecher G., Tamura K. 2016: MEGA7: Molecular Evolutionary Genetics Analysis version 7.0 for bigger datasets. Mol. Biol. Evol. 33: 1870-1874.

Laurimäe T., Kinkar L., Moks E., Romig T., Omer R.A., Casulli A., Umhang G., Bagrade G., Irshadullah M., Sharbatkhori M., Mirhendi H., Ponce-Gordo F., Soriano S.V., Varcasia A., Rostami-Nejad M., Andresiuk V., SAARma U. 2018a: Molecular phylogeny based on six nuclear genes suggests that Echinococcus granulosus sensu lato genotypes G6/G7 and G8/G10 can be regarded as two distinct species. Parasitology 145: 1929-1937.

Laurimäe T., Kinkar L., Romig T., Omer R.A., Casulli A., Umhang G., Gasser R.B., Jabbar A., Sharbatkhori M., Mirhendi H., Ponce-Gordo F., Lazzarini L.E., Soriano S.V., Varcasia A., Rostami-Nejad M., Andresiuk V., Maravilla P., Gonzalez L.M., Dybicz M., Gawor J., Šrarunas M., Šnabel V., Kuzmina T., SaArma U. 2018b: The benefits of analysing complete mitochondrial genomes: deep insights into the phylogeny and population structure of Echinococcus granulosus sensu lato genotypes G6 and G7. Infect. Genet. Evol. 64: 85-94.

Loi F., Berchialla P., Masu G., Masala G., Scaramozzino P., Carvelli A., Caligiuri V., Santi A., Bona M.C., Maresca C., Zanoni M.G., Capelli G., Iannetti S., Coccollone A., Cappai S., Rolesu S., Piseddu T. 2019: Prevalence estimation of Italian ovine cystic echinococcosis in slaughterhouses: a retrospective Bayesian data analysis, 2010-2015. PLoS ONE. 14: e0214224.

MCManus D.P. 2013: Current status of the genetics and molecular taxonomy of Echinococcus species. Parasitology 140: 1617-1623.
Meng X., Lindsay D., Sriranganathan N. 2009: Wild boars as sources for infectious diseases in livestock and humans. Phil. Trans. R. Soc. Lond. B Biol. Sci. 364: 2697-2707.

Mwambete K.D., Ponce-Gordo F., Cuesta-Bandera C. 2004: Genetic identification and host range of the Spanish strains of Echinococcus granulosus. Acta Trop. 91: 87-93.

Nakao M., McManus D.P., Schantz P.M., Craig P.S., Ito A. 2007: A molecular phylogeny of the genus Echinococcus inferred from complete mitochondrial genomes. Parasitology 134: $713-722$.

Namaware S.D., DahiYa S.S. 2018: First report on incidence of Echinococcus canadensis G6 strain from a dromedary camel of India. J. Camel Pract. Res. 25: 245.

Otero-Abad B., Torgerson P.R. 2013: A systematic review of the epidemiology of echinococcosis in domestic and wild animals. PLoS Neglected Trop. Dis. 7: e2249.

Paoletti B., Della Salda l., Di Cesare A., Iorio R., Vergara A., Olivastri A., Dessì G., Scala A., Varcasia A. 2019: Epidemiological survey on cystic echinococcosis in wild boar from Central Italy. Parasitol. Res. 118: 43-46.

Piseddu T., Brundu D., Stegel G., Loi F., Rolesu S., Masu G., Ledda S., Masala G. 2017: The disease burden of human cystic echinococcosis based on HDRs from 2001 to 2014 in Italy. PLoS Negl. Trop. Dis. 11: e0005771.

Rinaldi L., Maurelli M.P., Veneziano V., Capuano F., PeRUGini A.G., Cringoli S. 2008: The role of cattle in the epidemiology of Echinococcus granulosus in an endemic area of southern Italy. Parasitol. Res. 103: 175-179.

Saarma U., Jogisalu I., Moks E., Varcasia A., Lavikainen A., Oksanen A., Simsek S., Andresiuk V., Denegri G., Gonzalez L.M., Ferrer E., Garate T., Rinaldi L., MarAVILLA P. 2009: A novel phylogeny for the genus Echinococcus, based on nuclear data, challenges relationships based on mitochondrial evidence. Parasitology 136: 317-328.

Saitou N., Nei M. 1987: The neighbor-joining method: a new method for reconstructing phylogenetic trees. Mol. Biol. Evol. 4: 406-425.

Scala A., Varcasia A., Pipia A.P., Pilo C., Garippa G. 2006: First molecular isolation of Echinococcus granulosus horse strain (G4) in Sardinia (Italy). Parassitologia 48: 344.

Schurer J., Shury T., Leighton F., Jenkins E. 2013: Surveillance for Echinococcus canadensis genotypes in Canadian ungulates. Int. J. Parasitol. Parasites Wildl. 2: 97-101.

Seimenis A. 2003: Overview of the epidemiological situation on echinococcosis in the Mediterranean region. Acta Trop. 85: 191-195.

Sgroi G., Varcasia A., Dessi G., D’Alessio N., Tamponi C., Saarma U., Laurimäe T., Kinkar L., Santoro M., Caputo V., Sarnelli P., Fusco G., Varuzza P., Fioretti A., Scala A., Veneziano V. 2019: Cystic echinococcosis in wild boars (Sus scrofa) from southern Italy: epidemiological survey and molecular characterization. Int. J. Parasitol. Parasites Wildl. 9: $305-311$.

Soriano S.V., Pierangeli N.B., Pianciola L., Mazzeo M., Lazzarini L.E., Saiz M.S., Kossman A.V., Bergagna H.F., Chartier K., Basualdo J.A. 2010: Molecular characterization of Echinococcus isolates indicates goats as reservoir for Echinococcus canadensis G6 genotype in Neuquén, Patagonia Argentina. Parasitol. Int. 59: 626-628.

Tajima F., Nei M. 1984: Estimation of evolutionary distance between nucleotide sequences. Mol. Biol. Evol. 1: 269-285.

Thompson J.D., Higgins D.G., Gibson T.J. 1994: CLUSTAL W: improving the sensitivity of progressive multiple sequence alignment through sequence weighting, position-specific gap penalties and weight matrix choice. Nucl. Acids Res. 22: 4673-4680.

Thompson R.C., McManus D.P. 2002: Towards a taxonomic revision of the genus Echinococcus. Trends Parasitol. 18: 452-457. Varcasia A., Piseddu T., Pipia A.P., Schianchi G., Marongiu A., Petruzzi V., Scala A., Garippa G. 2008. Epidemiological and biomolecular updates on cystic echinococcosis in pigs 
and wild boars of Sardinia (Italy). Lucr. Stiintifice Med. Vet. 41: 385-387.

Veneziano V., Rinaldi L., Apicella G., Garippa G., CrinGOLI G., 2004: Cystic echinococcosis in the Campania region (southern Italy). Parassitologia 46: 449-451.

Wachira T.M., Bowles J., Zeyhle E., McManus D.P. 1993: Molecular examination of the sympatry and distribution of sheep and camel strains of Echinococcus granulosus in Kenya. Am. J. Trop. Med. Hyg. 48: 473-479.

Zhang L.H., Chai J.J., Jiao W., Osman Y., McManus D.P. 1998: Mitochondrial genomic markers confirm the presence of the camel strain (G6 genotype) of Echinococcus granulosus in north-western China. Parasitology 116: 29-33

Cite this article as: Pavia G., De Gori F., Ciambrone L., De Gori N., Musarella R., Casalinuovo F. 2020: Dispersal and molecular characterisation of the Echinococcus granulosus (Batsch, 1786) complex isolated from various intermediate hosts in the Calabria region, southern Italy. Folia Parasitol. 67: 014. 